\title{
Viability and pluripotency studying of human embryo stem cells labeled with quantum dots
}

\author{
Jing Ruan ${ }^{1}$, Jie Shen ${ }^{2}$, Hua Song ${ }^{1}$, Jiajia $\mathrm{Ji}^{1}$, Kan Wang ${ }^{1}$, Daxiang Cui ${ }^{1}$, Zheng Wang ${ }^{2 *}$ \\ ${ }^{1}$ Department of Bio-Nano Science and Engineering, Key Laboratory for Thin Film and Microfabrication Technology of Ministry of Education, \\ National Key Laboratory of Micro/Nano Fabrication Technology,Research Institute of Micro/Nano Science and Technology, Shanghai Jiao Tong \\ University, Shanghai,200240, P. R. China \\ ${ }^{2}$ Shanghai Institute of Digestive Diseases, Shanghai Renji Hospital, Shanghai Jiao Tong University School of Medicine, 145 Middle Shandong Road, \\ Shanghai 20001, P. R. China \\ *Corresponding author: zheng.w.dr@gmail.com
}

\begin{abstract}
Semiconductor quantum dots (QDs) hold increasing potential for cellular imaging both in vitro and in vivo. In this report, we aimed to study imaging of human embryonic stem (ES) cells labeled with quantum dots (QDs), and to evaluate the viability and pluripotency of human ES cells labeled with QDs. We used the Tat-QDs to label human ES cells, evaluated the cytoactivity of human ES cells labeled with QDs by CCK8 assay and Flow cytometer, and verified the pluripotency of human ES cells labeled with QDs by differentiated the human ES cells into hemangioblasts/blast cells and neural-like cells. The result illustrated that human embryonic stem (ES) cells were labeled with QDs and intracellular QD number was associated with the dose of QDs. Human ES cell viability, proliferation, and pluripotency were not adversely affected by QDs compared with non-labeled control cells. In summary, this is the first report showing the QDs labeled human ES cells could be differentiated into hemangioblasts/blast cells and neurallike cells. These results provide a promising tool for imaging stem cell therapy noninvasively in vivo.
\end{abstract}

Key Words: human embryo stem cells, quantum dots, label, cytoactive, pluripotency

Citation: J.Ruan et al.Viability and pluripotency studying of human embryo stem cells labeled with quantum dots. Nano Biomed. Eng. 2010, 2(4), 245-251. DOI: 10.5101/nbe.v2i4.p245-251.

\section{Introduction}

Stem cell therapy holds promise for treatment of intractable conditions such as Parkinson's disease, ischemic heart disease, diabetes, and degenerative joint diseases [1-4]. There are two types of cells used in stem cell therapy, adult stem cells and embryonic stem (ES) cells. Of the two, ES cells are the ultimate source for use in cell-based therapy because they possess a virtually unlimited capacity for self-renewal and pluripotency, which is defined as the ability to differentiate into all cell types, including neurons, cardiomyocytes, hepatocytes, islet cells, skeletal muscle cells, and endothelial cells [5]. In stem cell therapy, monitoring of cell survival and location after transplantation is important for determining their efficacy. With QDs' many advantages over traditional organic dyes, QDs may provide an excellent tool for imaging stem cell therapy.

Quantum dots (QDs) are nano-scale fluorescent semiconductors that are increasingly used as label tools in biological research. QDs have recently been utilized as fluorescent tags for label experiments in vivo and in vitro. They can be tailored, through control of size, composition, and shape, to provide broad spectral coverage with symmetric narrow emission profiles. QDs could be used as multicolor imaging applications and the tracking of live cells [6-7]. Reports in the literature suggest that QDs are noncytotoxic [8-9], while recent data suggests QD cytotoxicity due to different physicochemical properties, dose and exposure concentrations [10-14]. Most QD applications have utilized non-mammalian or cancer cells with only a few studies examining deleterious effects of QDs in human ES cells.

In this study, we used QDs to label human ES cells and illustrated QDs labeled human ES cells is useful for imaging stem cell therapy. We showed that labeling human ES cells with QDs does not adversely affect ES cell viability and proliferation. Finally, we successfully differentiated the QDs labeled human ES cells into hemangioblasts/blast cells and neural-like cells. 


\section{Materials and methods}

\subsection{Synthesis of CdTe quantum dots}

$5 \mathrm{mmol}$ of $\mathrm{CdCl}_{2} \cdot 2.5 \mathrm{H}_{2} \mathrm{O}$ was dissolved in $110 \mathrm{~mL}$ of water, and $12 \mathrm{mmol}$ of TGA were added under stirring, followed by adjusting the $\mathrm{pH}$ to 11 by dropwise addition of $1 \mathrm{molL}^{-1} \mathrm{NaOH}$ solution. The mixed solution was placed in a three-necked flask deaerated by $\mathrm{N}_{2}$ bubbling for $30 \mathrm{~min}$. Under stirring, $2.5 \mathrm{mmol}$ of oxygen-free NaHTe solution was injected into the three-necked flask, which was freshly prepared from tellurium powder and $\mathrm{NaBH}_{4}$ (molar rate of 1:2) in water at $0^{\circ} \mathrm{C}$. The resulting mixtures were refluxed at $100^{\circ} \mathrm{C}$ for $4 \mathrm{~h}$, the emitted wavelength is $580 \mathrm{~nm}$.

\section{2 preparation of TAT-QDs complex}

Endosomolytic Tat peptides[15] were prepared using a conventional solidphase, chemical synthesis method (GL Biochem, Shanghai, China) and have purity over $98 \%$. To prepare TAT-QDs complex, QDs were dispersed in 500 $\mu \mathrm{L}$ borate buffer (BB), $500 \mu \mathrm{L}$ EDC (44 mM in BB) and $400 \mu \mathrm{L} 2 \mathrm{mg} \mathrm{mL}^{-1} \mathrm{TAT}(\mathrm{In} \mathrm{BB})$ were added and vortexed, then allowed to react at room temperature for $3 \mathrm{~h}$ to obtain TAT-QDs. Oxidization of the endosomolytic Tat peptides was performed after mixing the TAT-QDs complex by airbubbling of pure oxygen gas flow for $30 \mathrm{~s}$, followed by shaking for $30 \mathrm{~min}$ in an Eppendorf thermomixer [16].

\subsection{Culture of human Embryo Stem cells}

The human Embryo Stem cell (hESC) line (H1) and Mouse Embryonic Fibroblast (MEF) cells (CF1) were pursued from Chinese Academy of Sciences (CAS). MEF cells were maintained in Dulbecco's modified eagle medium (DMEM, GIBCO) containing 10\% fetal bovine serum (FBS, GIBCO) and $1.0 \%$ penicillin and streptomycin (GIBCO). hESCs were maintained in hESC completed medium which made up with DMEM/F12 (GIBCO) supplemented with knockout SR (GIBCO), bFGF (Invitrogen), NEAA (GIBCO), L-glutamine (GIBCO) and $\beta$-mercaptoethanol (GIBCO). hESCs were cultured on MEF feeder cells dish which were coated with Matrigel(BD) in advance according to the standard human embryonic stem cell culture protocol [17].

\subsection{Labeling hESCs with Tat-QDs}

We trypsinized the human ES cells labeled with Tat-QDs. Growth medium containing different concentration of TatQDs $\left(0,0.01,1,5,10,20 \mathrm{nmolL}^{-1}\right)$ were respectively added to $1 \times 10^{6} \mathrm{hESCs}$ in suspension and incubated for $1 \mathrm{hr}$ at $37^{\circ} \mathrm{C}, 5 \% \mathrm{CO}_{2}$. hESCs were washed with PBS to remove any free Tat-QDs, resuspended in full growth media, plated and allowed to expand for $24 \mathrm{hrs}$. Fluorescence microscopy (NIKON TS100-F) observations of live cells were performed after $24 \mathrm{hrs}$. Labeled hESCs were analyzed by flow cytometry (FACSCalibur; BD Biosciences) using the FL2 channel to detect Tat-QDs labeled cells after $24 \mathrm{hrs}$.

\subsection{Effect of Tat-QDs on hESCs viability}

Human ES cells were cultured in the 96-well plate at the concentration of 5000 cells per well and incubated in a humidified $5 \% \mathrm{CO}_{2}$ balanced air incubator at $37^{\circ} \mathrm{C}$ for 24 h. Except from control wells, the remaining wells were added into Tat-QDs medium which final concentration are $0.01,1,5,10,20 \mathrm{nmolL}^{-1}$ respectively. Next from 1 day to 3 day, we measured the ODs using the Thermo multiskan MK3 ELISA plate reader according to the protocol of CCK8 assay and calculated the survival rate of cell. The survival rate of cells can be calculated by the following equation:

Cell viability $(\%)=$ optical density $(\mathrm{OD})$ of the treated cells/OD of the non-treated cells $\times 100$

To assess hESCs viability an Annexin-V-Fluos staining kit (Roche, Mannheim, Germany) and flow cytometry were used at 24, 72 and $120 \mathrm{hrs}$ post Tat-QDs labeling $(n=3$ cell isolations). The annexin assay identified hESCs undergoing apoptosis. Briefly, hESCs labeled with QDs were trypsinized, counted and washed with PBS. According to manufacturer's directions, AnnexinV-Fluos labeling solution was added to $2 \times 10^{5}$ cells in the Control, experimental groups $(0.01,1,20,50 \mathrm{nmol}$ $\left.\mathrm{L}^{-1}\right)$ and hESCs were analyzed on a flow cytometer with CellQuest software (BD Biosciences).

\subsection{Neural differentiation}

EB differentiation was performed by detaching human ES cells labeled with $5 \mathrm{nmolL}^{-1}$ Tat-QDs and culturing them in suspension on ultralow attachment plate for 8 days with EB differentiation medium. EBs at day 10 were treated with retinoic acid (Sigma, $0.1 \mu \mathrm{molL}^{-1}$ ) in DMEM/F12, $\mathrm{N}_{2}$ supplement (GIBCO), heparin (2 $\mu \mathrm{g}$ $\mathrm{mL}^{-1}$; Sigma) and cAMP $\left(1 \mu \mathrm{molL}^{-1}\right.$, Sigma $)$. One week later neuroepithelial rosettes were gently blown off and cultured on coverslips in the same medium in the presence of retinoic acid and sonic hedgehog (100ng $\mathrm{mL}^{-1}$; R\&D system) for another week. Cells plated on coverslips were washed with phosphate-buffered saline (PBS) and fixed with 4\% paraformaldehyde and 4\% sucrose. Permeabilization and blocking in $0.1 \%$ Triton, $5 \%$ fetal bovine serum (FBS) in Tris buffer for $40 \mathrm{~min}$ was followed by rabbit anti-nestin (1:200; Chemicon) antibodies $(2 \mathrm{~h})$ at room temperature and washed three times with blocking buffer, the secondary antibodies goat anti-rabbit Alexa-conjugated was applied to cells for $40 \mathrm{~min}$ at room temperature. For negative controls, first antibodies were omitted and the same staining procedures were followed.

\subsection{Hemangioblasts/blast cells differentiation}

Human ES cells were labeled with 5 nmolL $^{-1}$ TatQDs and cultures in ultralow attachment plate with EB differentiation medium. EBs were cultured in differentiation medium for 48 hours, and then half of the medium replaced with EB differentiation medium containing BMP4 (50 ng mL $\mathrm{m}^{-1}$ ), VEGF (50 $\left.\mathrm{ng} \mathrm{mL}^{-1}\right)$ and bFGF (20 ng mL ${ }^{-1}$ ). After 24-hour incubation, the EBs were collected and dissociated into cell pellet, then were plated in blast growth medium (BGM), and then incubated for up to 6 days. Hemangioblasts/blast cells suspensions from differentiated hESCs were labeled with CD45-APC (R\&D) and CD34-FITC (R\&D) antibodies from 10 day 
to 22 day. Day 6 hESC-blast cells were purified from blast cell cultures, the blast cells were resuspended in EB differentiation medium, mixed well with CFC medium. Cells in semi-solid CFU assay medium were plated into ultralow attachment plate for CFU colony growth. Cells were incubated in a $\mathrm{CO}_{2}$ incubator at $37^{\circ} \mathrm{C}$ up to 15 days. The formation of hematopoietic colonies was monitored microscopically.

\subsection{Statistical analysis}

Data were presented as mean \pm SD. For Statistical analysis, the 2-tailed Student t test was used. Differences were considered significant at $\mathrm{P}<0.05$.

\section{Result}

\subsection{Characterization of QDs}

As shown in Figure 1 (A), TEM exhibited that QDs are rather monodisperse, the average diameter of QDs was $3 \mathrm{~nm}$. After coupling Tat peptides with the QDs, the particles tended to aggregate together as shown in Figure 1 (B). The PL spectra of QDs and Tat-QDs were shown in Figure $1(\mathrm{C})$, the emission peak remained symmetric and had the high fluorescent intensity, the emission wavelength of Tat-QDs have blue shift compare to QDs. Figure 1 (D) showed strong red fluorescence under UV radiation .

\subsection{Intracellular Tat-QDs distribution in human ES cells}
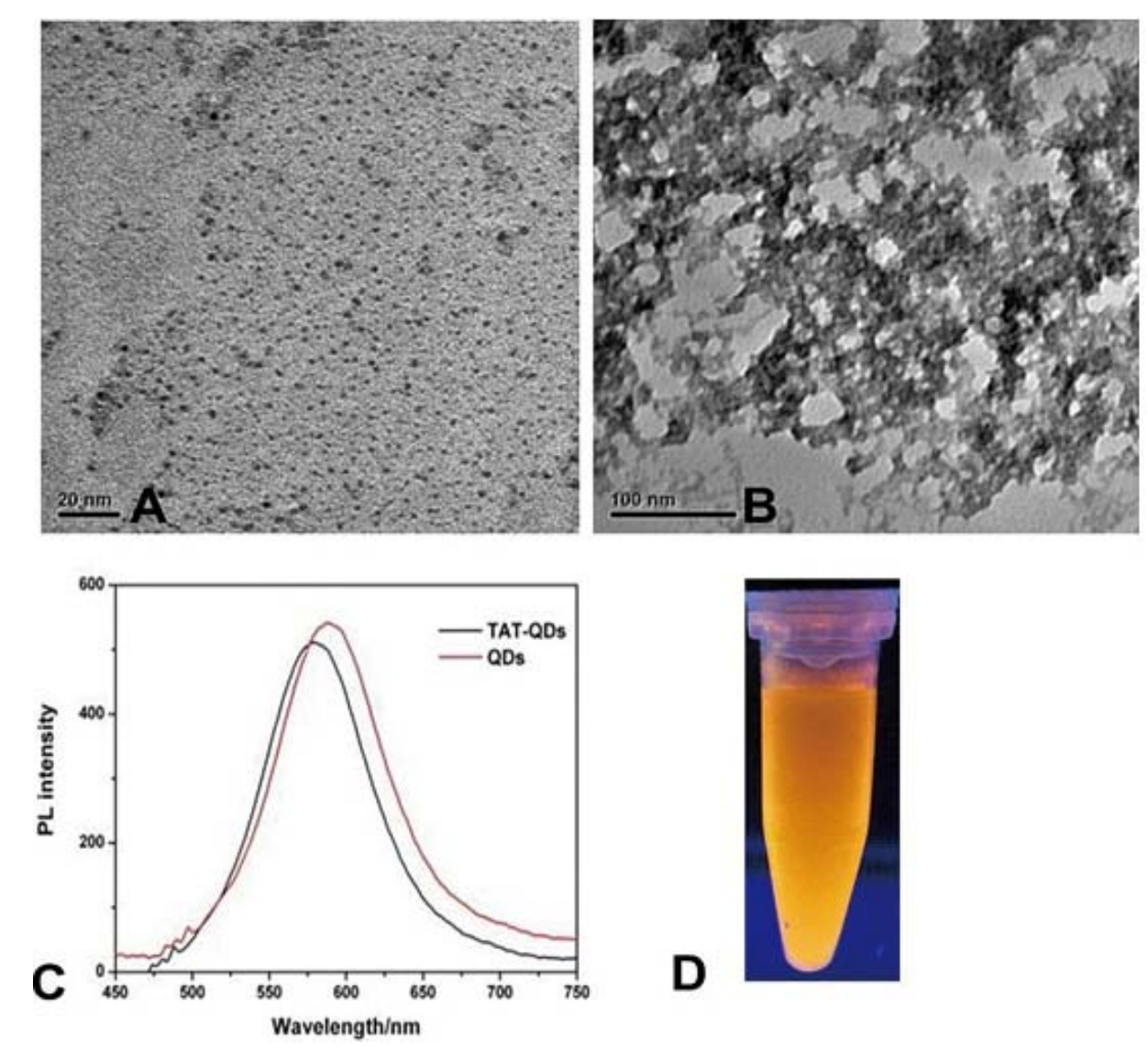

Flow cytometry and Fluorescent microscopy assessed intracellular Tat-QDs labeling at $24 \mathrm{hrs}$ in Control (no Tat-QDs). Flow cytometry analysis was used to quantitate intracellular QDs aggregates, a dose-dependent effect with increased QDs labeled human ES cells measured 24 hrs post Tat-QDs labeling, as shown in Figure 2, as more Tat-QDs were taken up by human ES cells, the fluorescence intensity increased, different concentration of Tat-QDs $\left(0,0.01,1,5,10,20 \mathrm{nmolL}^{-1}\right)$ labeled hESCs groups respectively express $0.51 \%, 13.9 \%, 22.2 \%, 74 \%$, $75.9 \%$ and $92.5 \%$ positive signals. Fluorescent images were used to detect intracellular QDs aggregates, Figure 3 illustrated QDs location and distribution in live hESCs at $24 \mathrm{hrs}$ post labeling. For each group $(0,0.01,1,5,10,20$ $\left.\mathrm{nmolL}^{-1}\right)$ QDs were detected with fluorescent microscopy, and the fluorescent signals increased with the Tat-QDs concentration increased.

\subsection{Effect of Tat-QDs on human ES cells viability}

Toxicity of Tat-QDs is a key factor in determining whether it will be a feasible probe for both cellular and clinical use. We carefully examined the effect of TatQDs on human ES cells by CCK8 assay. Figure 4(A) shows the percentage of live cells in triplicates at 24,48 and 72 hours post Tat-QDs labeling. Overall, there was no significant difference between labeled and unlabeled ES cells. To determine whether Tat-QDs induced human ES cells apoptosis, human ES cells were labeled with Annexin V and flow cytometry analysis assessed human ES cells viability identifying apoptosis in the cell

Figure 1 Characterization of QDs. (A) TEM image of QDs, (B) TEM image of Tat-QDs, (C) PL spectra of QDs and Tat-QDs, (D) The fluorescent image of QDs under UV irradiation. 

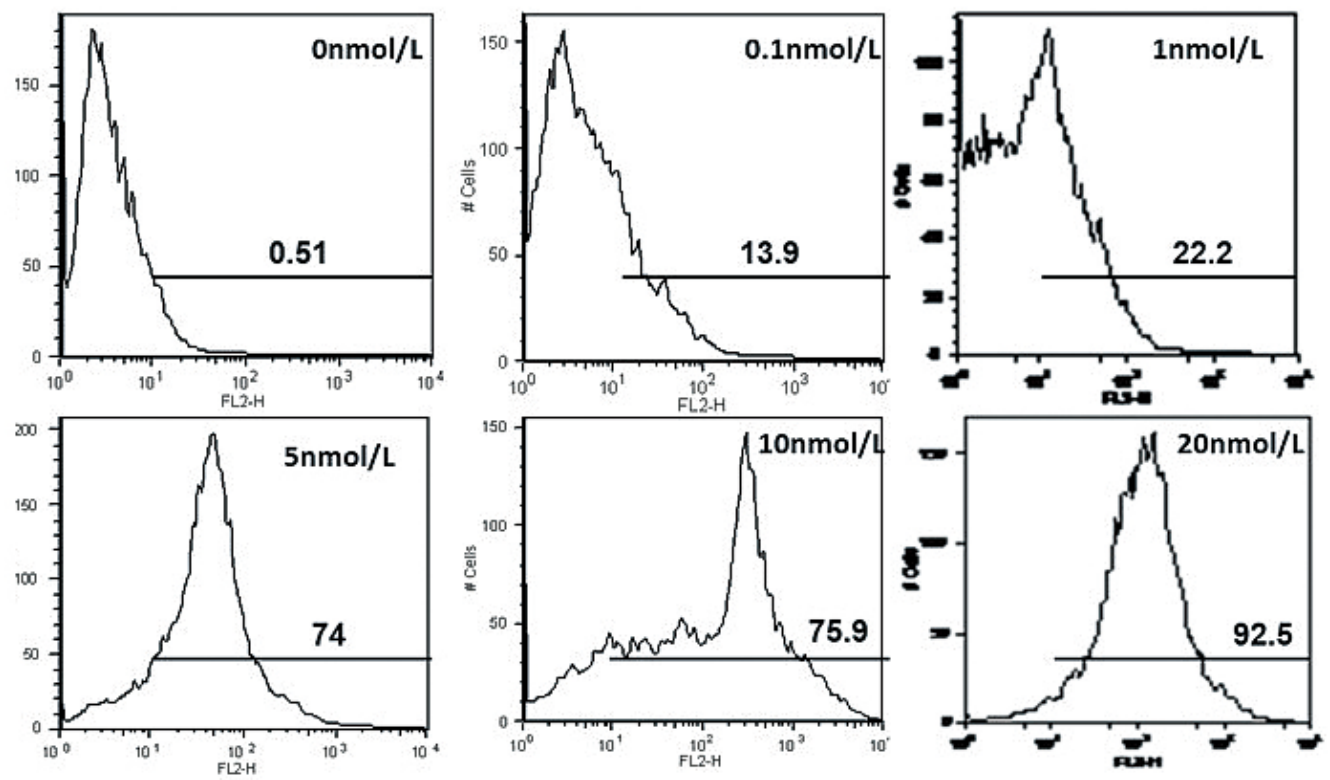

Figure 2 Flow cytometry analysis the amount of human ES cells are labeled with different concentration of Tat-QDs.
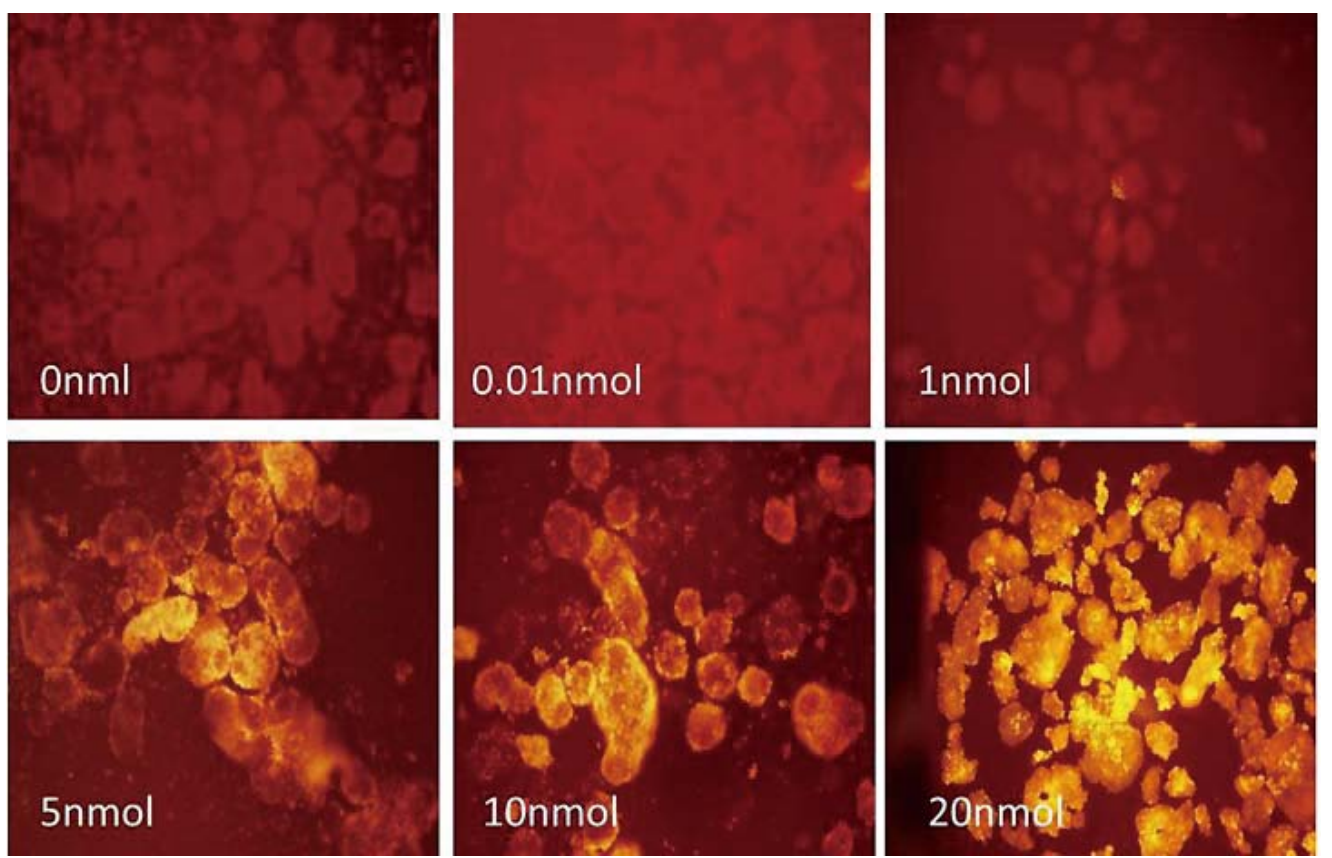

Figure 3 The microscopy image of human ES cells labeled with different concentration of Tat-QDs presenting red fluorescence inside of the cells

population post Tat-QDs labeling. As shown in Figure 4(B), above $90 \%$ of Tat-QDs labeled human ES cells were viable, seldom apoptosis signal occurred.

\subsection{Inducing hESC differentiation into neural-like cells}

Human ES lines labeled with $5 \mathrm{nmolL}^{-1}$ Tat-QDs were cultured with serum replacement medium (Figure 5(A)). We also pursued neuron differentiation of EBs (Figure 5(B)) from human ES cells labeled with $5 \mathrm{nmolL}^{-1}$ TatQDs [18]. Neural rosettes (Figure 5(C)) containing neural stem cells were first generated after 10 days that stained positively for nestin (Figure 5(D, E)). After an additional 2 weeks with added retinoic acid and sonic hedgehog, neural-like cells appeared as shown in Figure 5(F).

\subsection{Inducing hESC differentiation into hemangioblasts /blast cells}

EB cells were plated in blast-growth/expansion medium (BGM) for the development of blast cells [19]. EB cells developed blast colonies six days after plating (Figure 6(A)), within these areas of differentiation were regions of cobblestone-type cells and other areas of small, round loosely adherent cells. Differentiation initiated almost exclusively from the middle of the colonies, reproducibly yielding colonies with a tripartite morphology consisting of a dark inner center, an intermediate layer, and a white outer layer. These tripartite colonies often grew to very large sizes but retained their morphologies (Figure $6(\mathrm{~B}, \mathrm{C}))$. After replating in hematopoietic colonyforming media for 10 to 14 days, erythroid (CFU-E) hematopoietic cell colonies developed (Figure 6(D)). These hemangioblasts/blast cells from hESCs expressed hemangioblast markers CD45 (Figure 6(E)), but majority of these hemangioblasts/blast cells did not express CD34 as demonstrated by flow cytometry. 

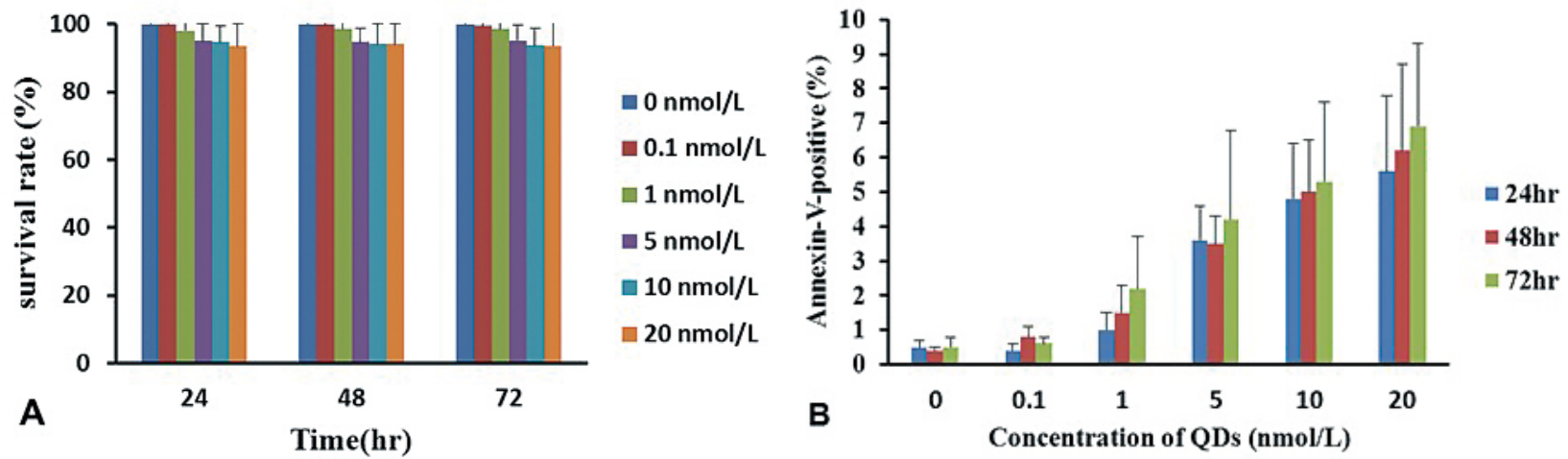

Figure 4 Effect of Tat-QDs on human ES cells viability. (A) CCK8 assays illustrating cell survival rate upon exposing human ES cells to different concentration of Tat-QDs for 24, 48 and $72 \mathrm{hrs,} \mathrm{(B)} \mathrm{Flow} \mathrm{cytometry} \mathrm{analysis} \mathrm{of} \mathrm{the} \mathrm{percent} \mathrm{of} \mathrm{apoptotic} \mathrm{cells,} \mathrm{annexin} \mathrm{positive} \mathrm{Tat-QDs} \mathrm{labeled}$ human ES cells.
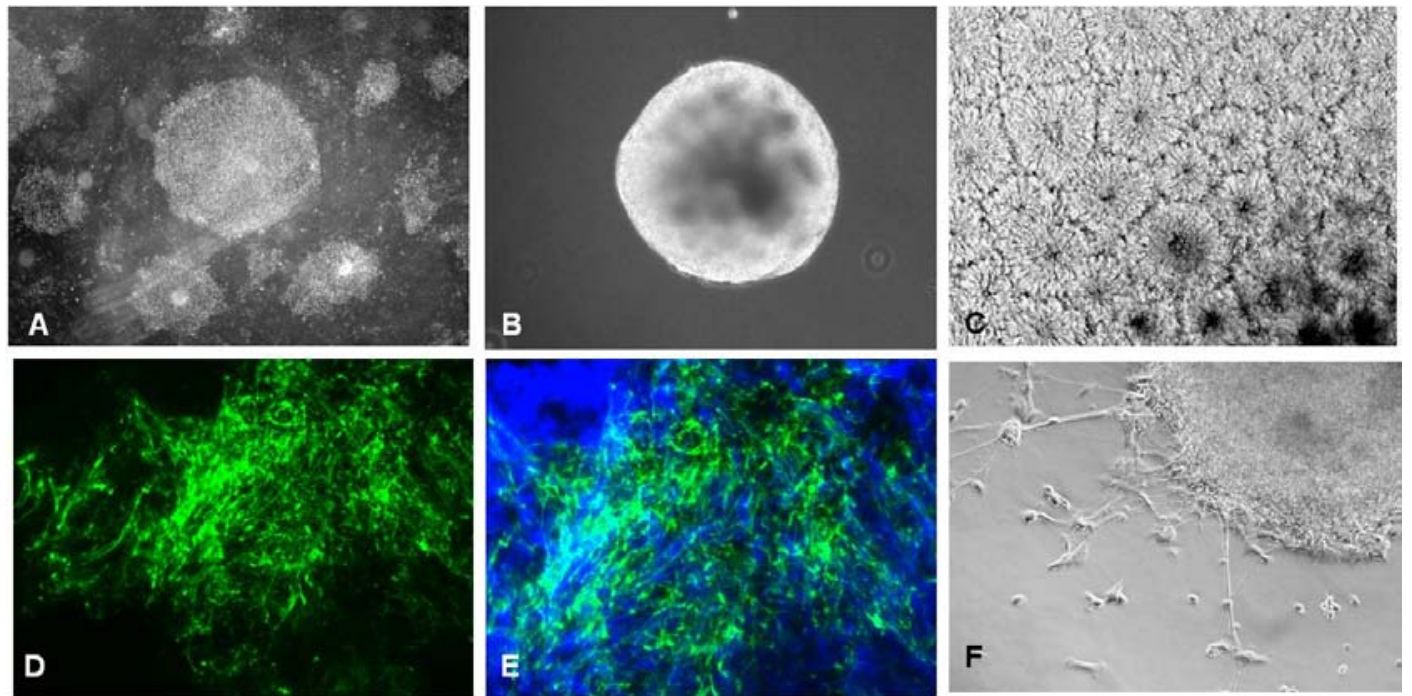

Figure 5 Neural-like cells differentiation. (A) Representative phase contrast images of human ES cells labeled with $5 \mathrm{nmol} \mathrm{L} \mathrm{L}^{-1}$ Tat-QDs, (B) Phase contrast photographs of EB, (C)Phase contrast photographs of neural rosettes from hESC-derived EBs, (D) Immunofluorescence staining for the neural stem cell marker nestin, (E) DAPI is shown in blue for immunofluorescence, (F) Phase contrast photographs of neural-like cells.
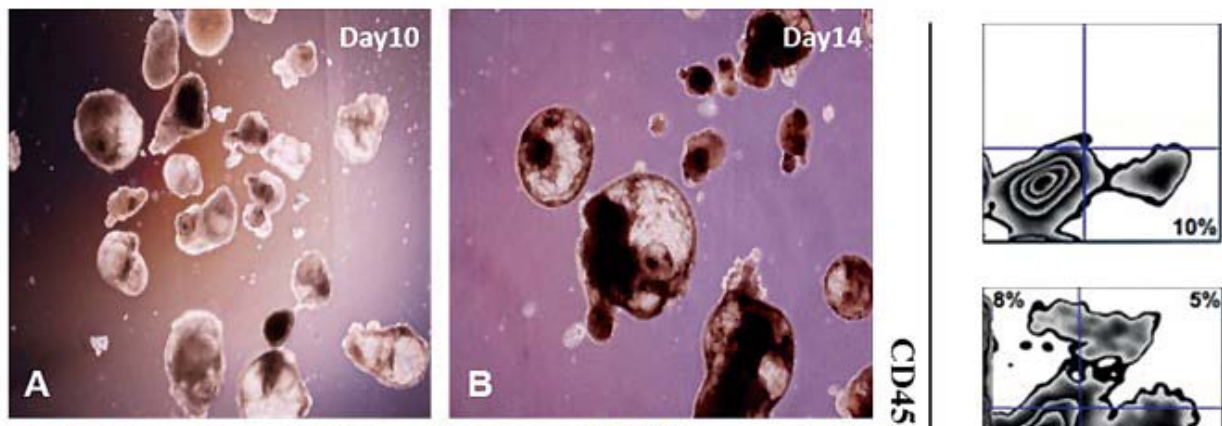

\section{Day10}
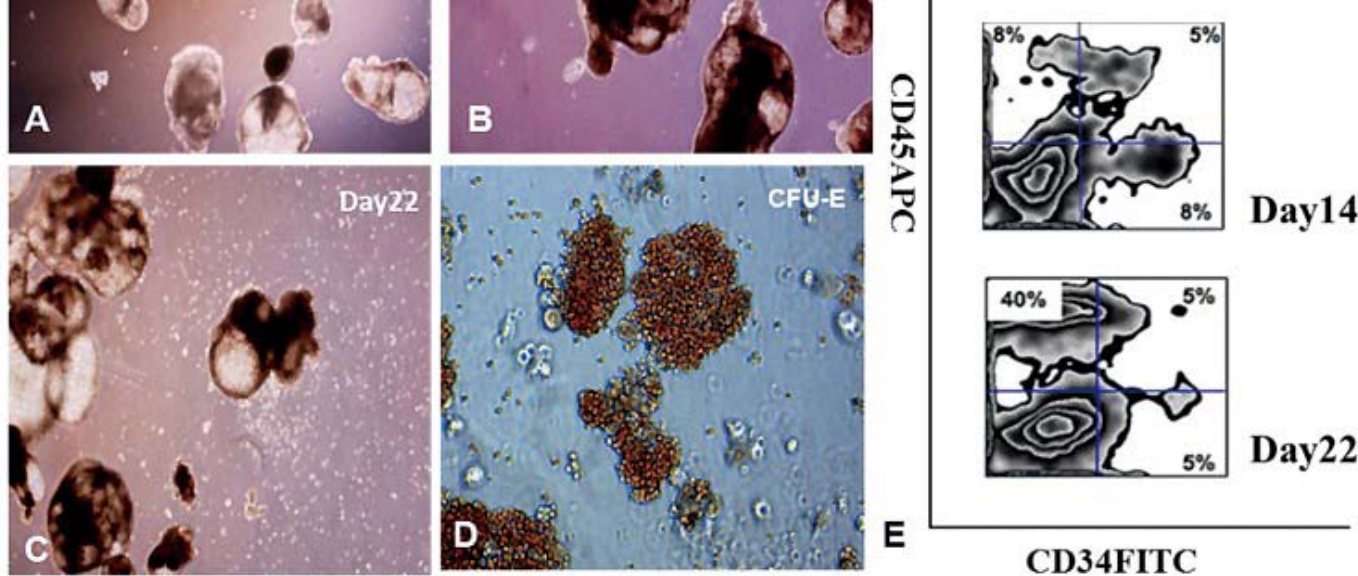

Figure 6 Photographs of hematopoietic colonies and cells derived from H1/S17 cells. (A-C)The morphology of hematopoietic cells differentiates from H1/S17 cells for 10, 14 and 22 days, (D) The morphology of CFU- erythroid colonies, (E) Analysis of CD45 and CD34 expression by flow cytometry. 


\section{Discussion}

Stem cells offer an exciting new branch of therapy to treat a variety of conditions and diseases [20-21]. It is therefore important to develop methods to monitor cell survival and location after transplantation. Due to its many advantages over conventional organic dyes, QDs serve as good candidates to monitor cells. Strategies for in vitro cell labeling by QDs include nonspecific endocytosis, microinjection, liposome mediated uptake, electroporation, and peptidebased reagents. Previous studies have shown that the liposome-based reagent Lipofectamin 2000 had the highest delivery efficiency, but the QDs were delivered in aggregates [22]. Electroporation also delivered QDs in aggregates, and may even cause cell death. Peptide-based QDs deliver QDs into the live cells, and have been shown to be an excellent and easy tool for studying live cell mobility [23] and cell fusion [24].

The Peptide-based QDs combined QDs with a custom targeting Tat peptide to improve QD solubility and intracellular delivery. With this delivery system QDs had the tendency to aggregate and intracellular QDs aggregates were more abundant at higher TatQDs concentrations. This increase in intracellular QDs aggregate size and number may have contributed to the observed dose effects. It is possible that lower Tat-QDs concentrations and longer exposure times may yield smaller QDs aggregates and reduced cytotoxic effects with similar QDs labeling yield. The development of cell-penetrating QDs may require lower Tat-QDs labeling concentrations, while factors such as surface charge, QDs size and incubation media have been identified as important for uniform and complete labeling. In addition, reports suggest that QDs are sensitive to environmental factors such as $\mathrm{pH}$, salts, oxidation and temperature [25-26]. These factors were not evaluated but should be considered when used with human ES cells for in vitro and in vivo applications.

In this report, we evaluated the effect of Tat-QDs on human ES cells. Twenty-four hours after labeling human ES cells with Tat-QDs, $92.5 \%$ of the cells were positive. One important question is whether QDs affect human ES cell properties (pluripotency and self-renewal) that make them an attractive choice for regenerative therapy. Previous studies have shown that QD exposure did not interfere with metabolic activity or significantly affect DNA structure at lower QD concentration [27]. However, at the higher QD concentration, it will induce dose-dependent increase in cell apoptosis. Therefore, we examined human ES cell proliferation and viability at different Tat-QDs concentration $(0,0.1,1,5,10$, $\left.20 \mathrm{nmolL}^{-1}\right)$ and observed no significant changes between Tat-QDs labeled ES cells and control unlabeled ES cells. These results showed QDs have no adverse effects on the viability and morphology of cells among these concentrations. These results suggest that when using QDs to label and track stem cells, QD concentration and exposure time should be optimized to reduce cytotoxic effects.
In order to verity the pluripotency of human ES cells, we also induced Tat-QDs labeled human ES cells differentiation into hemangioblasts/blast cells and neurallike cells, the differentiated human ES cells respectively express CD45, and nestin [28-31], it illustrated that QDs labeled human ES cells also have pluripotency.

\section{Conclusion}

In summary, we labeled human ES cells with QDs and evaluated the cytoactivity of cells. We have shown that it is feasible to label human ES cells with QDs high efficiency. QDs labeled human ES cells were bright, photostable and easy to track in live co-cultures providing the opportunity for regenerative medicine studies. After labeling, QDs did not affect the viability, and have no adverse effect on pluripotency of human ES cells. This is the first report showing the QDs labeled human ES cells were differentiated into hemangioblasts/blast cells and neurallike cells. It will lay the foundation for future applications of QDs in stem cells. In addition to long term in vivo cell tracking and imaging, it still have long road to go.

\section{Acknowledgement}

This work was supported by the National Natural Science Foundation of China (No.20803040 and No.20471599), Chinese 973 Project (2010CB933901), New Century Excellent Talent of Ministry of Education of China(NCET-08-0350), Special Infection Diseases Key Project of China (2009ZX10004-311), Shanghai Science and Technology Fund (10XD1406100), and Doctoral Program of Higher Education Research Fund(20070248050, 20070248107).

\section{References}

1. Bruder S, Kurth A, Shea M, Hayes W, Jaiswal N, Kadiyala S. Bone regeneration by implantation of purified, culture expanded human mesenchymal stem cells. J. Orthopaedic Res. 1998;16:155-162. doi:10.1002/jor.1100160202

2. Lindvall O, Kokaia Z, Martinez-Serrano A. Stem cell therapy for human neurodegenerative disorders"Chow to make it work. 2004.

3. Soria B, Skoudy A, Martin F. From stem cells to beta cells: new strategies in cell therapy of diabetes mellitus. Diabetologia. 2001;44:407-415. doi:10.1007/s001250051636

4. Strauer B, Kornowski R. Stem cell therapy in perspective. Circulation. 2003;107:929. doi:10.1161/01.CIR.0000057525. 13182.24

5. Fuchs E, Segre J. Stem cells: a new lease on life. Cell. 2000;100: 143-156.

6. Muller-Borer B, Collins M, Gunst P, Cascio W, Kypson A. Quantum dot labeling of mesenchymal stem cells. J. Nanobiotechnol. 2007; 5 .

7. Zheng J, Ghazani A, Song Q, Mardyani S, Chan W, Wang C. Cellular imaging and surface marker labeling of hematopoietic cells using quantum dot bioconjugates. Lab. Hematology. 2006;12:94-98. doi:10.1532/LH96.04073

8. Dubertret B, Skourides P, Norris D, Noireaux V, Brivanlou A, Libchaber A. In vivo imaging of quantum dots encapsulated in phospholipid micelles. Science. 2002;298:1759. doi:10.1126/ science. 1077194

9. Jaiswal J, Mattoussi H, Mauro J, Simon S. Long-term multiple color imaging of live cells using quantum dot bioconjugates. Nat. Biotechnol. 2002;21:47-51. doi:10.1038/nbt767

10.Braydich-Stolle L, Hussain S, Schlager J, Hofmann M. In vitro cytotoxicity of nanoparticles in mammalian germline stem cells. Toxicol. Sci. 2005;88:412. doi:10.1093/toxsci/kfi256

11.Hardman R. A toxicologic review of quantum dots: toxicity 
depends on physicochemical and environmental factors. Environ. Health Perspect. 2006;114:165. doi:10.1289/ehp.8284

12.Hsieh S, Wang F, Hung S, Chen Y, Wang Y. The internalized CdSe/ $\mathrm{ZnS}$ quantum dots impair the chondrogenesis of bone marrow mesenchymal stem cells. J. Biomed. Mater. Res., Part B: Appl. Biomater. 2006;79:95-101. doi:10.1002/jbm.b.30517

13.Lovric J, Cho S, Winnik F, Maysinger D. Unmodified cadmium telluride quantum dots induce reactive oxygen species formation leading to multiple organelle damage and cell death.Chem. Biology. 2005; 12:1227-1234. doi:10.1016/j.chembiol.2005.09.008

14. Seleverstov O, Zabirnyk O, Zscharnack M, Bulavina L, Nowicki $\mathrm{M}$, Heinrich J, et al. Quantum dots for human mesenchymal stem cells labeling. A size-dependent autophagy activation. Nano Lett. 2006;6:2826-2832. doi:10.1021/n10619711

15.Lo S, Wang S. An endosomolytic Tat peptide produced by incorporation of histidine and cysteine residues as a nonviral vector for DNA transfection. Biomaterials. 2008;29:2408-2414. doi:10.1016/j.biomaterials.2008.01.031

16. Song H, Yang J, Lo S, Wang Y, Fan W, Tang X, et al. Gene transfer using self-assembled ternary complexes of cationic magnetic nanoparticles, plasmid DNA and cell-penetrating Tat peptide. Biomaterials. 2010;31:769-778. doi:10.1016/ j. biomaterials.2009.09.085

17.Thomson J, Itskovitz-Eldor J, Shapiro S, Waknitz M, Swiergiel $\mathrm{J}$, Marshall V, et al. Embryonic stem cell lines derived from human blastocysts. Science. 1998;282:1145. doi:10.1126/ science.282.5391.1145

18.Cai J, Li W, Su H, Qin H, Yang J, Zhu F, et al. Generation of Human Induced Pluripotent Stem Cells from Umbilical Cord Matrix and Amniotic Membrane Mesenchymal Cells. J. Biol Chem. 2010;285(15):11227-11234. doi: 10.1074/jbc.M109.086389

19.Feng Q, Lu S, Klimanskaya I, Gomes I, Kim D, Chung Y, et al. Hemangioblastic Derivatives from Human Induced Pluripotent Stem Cells Exhibit Limited Expansion and Early Senescence. Stem cells. 2010;28(4):704-712. doi:10.1002/stem.321

22.Wang Z, Ruan J, Cui D. Advances and Prospect of Nanotechnology in Stem Cells. Nanoscale Res. Lett. 2009;4:593-605. doi:10.1007/s11671-009-9292-z

23.Ji J, Ruan J, Cui D. Advances of nanotechnology in the stem cells research and development. Nano Biomed.Eng. 2010;2:67.

24.Lin S, Xie X, Patel M, Yang Y, Li Z, Cao F, et al. Quantum dot imaging for embryonic stem cells. BMC biotechnol. 2007; 7:67. doi:10.1186/1472-6750-7-67

25.Derfus A, Chan W, Bhatia S. Probing the cytotoxicity of semiconductor quantum dots. Nano lett. 2004;4:11-18. doi:10. $1021 /$ n10347334

26.Murasawa S, Kawamoto A, Horii M, Nakamori S, Asahara T. Nichedependent translineage commitment of endothelial progenitor cells, not cell fusion in general, into myocardial lineage cells. Arteriosclerosis, thrombosis, and vascular biology. 2005;25:1388 doi:10.1161/01. ATV.0000168409.69960.e9

27. Sun Y, Vernier P, Liang C, Chong S, Gundersen M. pH-sensitive photoluminescence of $\mathrm{CdSe} / \mathrm{ZnSe} / \mathrm{ZnS}$ quantum dots in human ovarian cancer cells. J. Phys. Chem. C. 2007;111:2872-2878. doi:10.1021/jp0654718

28.Lagerholm B, Wang M, Ernst L, Ly D, Liu H, Bruchez M, et al. Multicolor coding of cells with cationic peptide coated quantum dots. Nano lett. 2004;4:2019-2022. doi:10.1021/n1049295v

29.Lewinski N, Colvin V, Drezek R. Cytotoxicity of nanoparticles. Small. 2008;4:26-49. doi:10.1002/smll.200700595

30.Qiu C, Hanson E, Olivier E, Inada M, Kaufman D, Gupta $\mathrm{S}$, et al. Differentiation of human embryonic stem cells into hematopoietic cells by coculture with human fetal liver cells recapitulates the globin switch thatoccurs early in development. Experimental hematology.2005;33:1450-1458. doi:10. 1016/j.exphem.2005.09.003

31.Perrier A, Tabar V, Barberi T, Rubio M, Bruses J, Topf N, et al. Derivation of midbrain dopamine neurons from human embryonic stem cells. Proc. Natl. Acad. Sci. U. S. A. 2004;101:12543. doi:10.1073/pnas.0404700101

32.Francis K, Wei L. Human embryonic stem cell neural differentiation and enhanced cell survival promoted by hypoxic preconditioning. Cell Death \& Disease. 2010; 1:22.

33. Shin S, Dalton S, Stice S. Human motor neuron differentiation from human embryonic stem cells. Stem Cells Dev. 2005;14:266-269. doi:10.1089/scd.2005.14.266

Received 10 November, 2010; accepted 6 December, 2010; published online 16 December, 2010.

Copyright: (c) 2010 Jing Ruan, et al. This is an open-access article distributed under the terms of the Creative Commons Attribution License, which permits unrestricted use, distribution, and reproduction in any medium, provided the original author and source are credited. 